\title{
Street Foods in Central Kenya: Actors, Trends, and Opportunities
}

\author{
Paulina Moussavi \\ Department of Public Relations \\ The Pennsylvania State University \\ University Park, PA 16802 \\ Pmoussavi16@gmail.com
}

\author{
Krista Liguori \\ Biology Department \\ The Pennsylvania State University \\ University Park, PA 16802 \\ krista.liguori@gmail.com
}

\author{
Khanjan Mehta* \\ Humanitarian Engineering and Social Entrepreneurship (HESE) Program \\ The Pennsylvania State University \\ University Park, PA 16802 \\ khanjan@engr.psu.edu \\ *Corresponding Author
}

\begin{abstract}
Street foods served by vendors and hawkers are a popular snack or meal in most developing countries due to the industry's widespread benefits. Benefits for vendors include low start-up costs, flexible schedules, and a fast return on investment, while benefits for consumers include affordability, fast service, and ease of accessibility, illustrating their symbiotic relationship. In many regions however, street foods lack adequate nutrition due to price and infrastructural constraints. Where street foods make up a significant portion of peoples' diets, factors such as price, availability, and preparation method have direct implications on the economic status, food security, and health of a community. Research conducted in Nyeri, Kenya demonstrates the motivations behind buying and selling street foods, social and economic factors that influence these patterns, and their impact on vendors' livelihoods, women's empowerment, and consumer food options. This study, based on interviews with 50 street food vendors and 50 street food consumers who, moderately to regularly, buy and sell street foods, outlines the local street food market, obstacles faced by vendors, and recommendations for increasing the industries healthiness and social acceptance. General recommendations include social and political advancements, legal protections, education programs, and opportunities related to health innovation.
\end{abstract}

Index Terms- Entrepreneurship, Food Security, Community Health, Street Foods

\section{INTRODUCTION}

An estimated 2.5 billion people consume street foods everyday around the world. ${ }^{1}$ One can walk the streets of almost any country and find a variety of street foods, from moi-moi, a typical fried bean cake in Nigeria, to momo, a dumpling native to Nepal, to cuy, a species of guinea pig in Peru. The Food and Agriculture Organization (FAO) defines street foods as "ready-to-eat foods and beverages prepared and/or sold by vendors and hawkers especially in streets and other similar public places." These foods serve as convenient, quick, and affordable snacks or meals 
International Journal for Service Learning in Engineering, Humanitarian Engineering and Social Entrepreneurship Vol. 11, No. 2, pp. 87-100, Fall 2016

ISSN 1555-9033

for customers of all ages and socioeconomic statuses. Street foods are a popular source of sustenance for both urban and rural dwellers, particularly for those who lead busy lives due to work, school, or caring for family.

Street foods play a crucial role in food security for millions of low and middle-income individuals in developing countries. For example, residents of provincial towns in Nigeria and Thailand spend nearly half of their average household food budget on street foods. ${ }^{2}$ In the Philippines and Indonesia, this expense is nearly a quarter of the household food budget. ${ }^{2}$ In lowincome areas, vendors serve up to three times as many customers, charge 10-30\% less, and work more flexible hours than in higher income areas. ${ }^{3}$

As economies develop, more women are engaging in activities outside the home to financially contribute to their household. ${ }^{4}$ With more women than ever actively involved in income-generating activities outside the household, the traditional pattern of women caretakers who cook and provide all family meals is becoming gradually less common. This has led some families, especially children, to rely more on processed street foods. ${ }^{5}$

A study conducted in northern Tanzania found $70 \%$ of the interviewed female food vendors maintained long-term business relationships with other female vendors and valued these longterm relationships based on trust and respect rather than competition. ${ }^{6}$ This article discusses various ways in which the street food industry can be of great benefit to women in many lowincome developing countries by increasing their social and economic capital, facilitating professional and personal networks, and otherwise empowering them. ${ }^{6}$

\section{The Need for More Nutritious Street Foods}

Malnutrition is one of the leading causes of mortality in developing countries. In sub- Saharan Africa, one in four individuals are malnourished, the highest rate in any region of the world. ${ }^{7}$ Providing balanced diets with sufficient nutrients is thus a vital factor in improving community wellbeing and development. A study conducted in two sections of Nairobi concluded that food vendors in Kangemi and Dandora sold 79\% carbohydrate-based products - a disproportionate percentage when compared to other food groups. ${ }^{4}$ Many of the culturally popular and affordable staple foods such as ugali (flour porridge), uji (maize porridges), and mandazi (fried doughnut) are high in carbohydrates and starch, and tend to lack the nutritional content needed to provide a balanced diet if not supplemented with other nutrient-rich foods throughout the day. ${ }^{8}$ Examining the health consequences of street food consumption is important, as more children are habitually eating these foods from a younger age for various economic and social reasons.

Challenges obtaining proper nutrition are related to high unemployment rates and the uncertainty of agricultural yields due to climate change. ${ }^{9}$ Kenyans depend heavily on agriculture as a source of income and food. However, inconsistent yields, inefficient harvesting, inadequate transportation, and poor infrastructure lead to produce frequently being mishandled and improperly stored, resulting in excess waste. ${ }^{10}$ Inefficiencies in food supply chains increase end prices for consumers and thus reduce access to fresh, healthy foods. ${ }^{10}$ Improvements to agriculture through the introduction of simple technologies, such as drip irrigation and applications that track key temperatures for farmers affected by changing climates, have the potential for rippling positive effects on food security.

While street vending is an essential component of global food security, this informal sector is largely under-acknowledged due to misconceptions regarding the nature of the business, sanitation, and social contributions. ${ }^{10}$ Primary misconceptions are that street vending jobs are 
International Journal for Service Learning in Engineering, Humanitarian Engineering and Social Entrepreneurship Vol. 11, No. 2, pp. 87-100, Fall 2016

ISSN 1555-9033

temporary positions; street vendors consume public space; only poor people consume street foods; only women work as street vendors; street foods are not a major component of dietary intake; and street foods are unsanitary and dangerous to eat. ${ }^{11}$ While some of these concerns may be valid in certain settings, street foods nonetheless provide an affordable and accessible source of food security and employment for low-income individuals.

A consumer's ability to access foods, in particular those that are needed to fulfill a variety of basic health requirements, is directly related to their socioeconomic status and income level. ${ }^{4}$ Overall, poor families tend to spend a higher percentage of their income on food, particularly street food, often leading to an unbalanced diet. ${ }^{2}$ Research in West Africa has shown that individuals who frequently eat street foods are considerably more likely to have diets consisting of saturated fats, trans-fatty acids, sugar, salt, and high-density carbohydrates. ${ }^{11}$ A study conducted in Nairobi, which investigated nutritional contributions of street foods, found that non-home prepared foods constituted $13-36 \%$ of dietary energy, 11-20\% of vitamin A intake, and $7-20 \%$ of iron intake for urban residents. ${ }^{12}$ These contributions signify that this population is heavily reliant on street food, receiving up to one third of their daily energy from street foods. ${ }^{13}$ A separate study also found that more than $40 \%$ of households in Nairobi's low-income neighborhoods consume street foods. ${ }^{4}$ While each individual's dietary health can only be determined from examining the entirety of their diet, street foods are not providing enough nutrients for those relying on them frequently. These previous research efforts illustrate the significant impact street foods have on the diets of low-income consumers and the need to introduce healthier street foods to prevent malnutrition.

Through analysis of business trends around current street foods in Kenya and the relationship between vendors and consumers, this article seeks to raise awareness about the ways stakeholders can improve vendors' livelihoods and consumers' nutrition. By providing information on women's economic and social potential in this sector, this article touches on the various ways the street food industry can empower women. This research is useful for individuals interested in small-business supply chain operations, current social and economic patterns of vending and consumption, innovating with simple technologies, and perspectives and limitations of street foods. The dissemination of this knowledge can aid governmental and nongovernmental organizations in helping vendors and suppliers to develop improved business strategies, which in turn can ultimately encourage and increase the chances that the vendors offer healthier foods whilst seeking increased profits.

\section{MATERIALS AND METHODS}

\section{Interview Methodology}

In order to gain the most accurate local representation of the industry, oral interviews were conducted with 50 street food vendors and 50 consumers between the ages of 20 and 70 in the town center of Nyeri, Kenya over a three-week period. These cross-sectional interviews are qualitative in order to understand the current underlying opinions and motivations of street vendors and consumers. Participants were asked a series of questions in the same order, responses to which were recorded in a journal by one of two interviewers present. Street vendors and consumers were identified within one spatial area, in which every participant that fit our criteria (street food vendors and local consumers) was requested for an interview. The spatial area selected was central to work, school, public transportation, dining, and other public areas. 
Street vendors were interviewed regarding the foods they sold, preparation methods, suppliers, profit margins, relationships with customers, stocking frequency, cart acquisition, selling location, and license fees. Consumers were interviewed with regard to their average street food intake, most commonly purchased street foods, relationships to vendors, and personal opinions on the informal sector. Participation was voluntary and non-compensated. No sensitive information was collected from any of the participants, nor was data easily identifiable.

In order to compare the available options for consumers, data was gathered on the offerings and prices from 15 appetizer menus of local cafés and restaurants. These establishments use setprice menus; haggling is not expected. Appetizers were examined instead of main dishes, as these are more comparable to street foods in regards to recipe and price. Data was collected by study personnel at restaurant visits. Key parameters obtained from each point of sale included price, a list of menu offerings, and frequency of sale for each dish. Paper records were entered into a Microsoft Excel spreadsheet for data management and qualitative analysis. After data input, outcomes were coded and analyzed for response frequency and range. Restaurant data was compared to their street food equivalents in regards to price and frequency.

\section{RESULTS}

After interviewing a total of 50 street food vendors in Nyeri, the most common type of vendors were those who sold whole fruit or individual slices, especially pineapple, watermelon, bananas, and oranges. The second most popular street foods available were fried meat, most notably samosas (fried vegetable/meat pastry), miniature kebabs, and smokies, miniature sausages served with kachumbari (salsa).

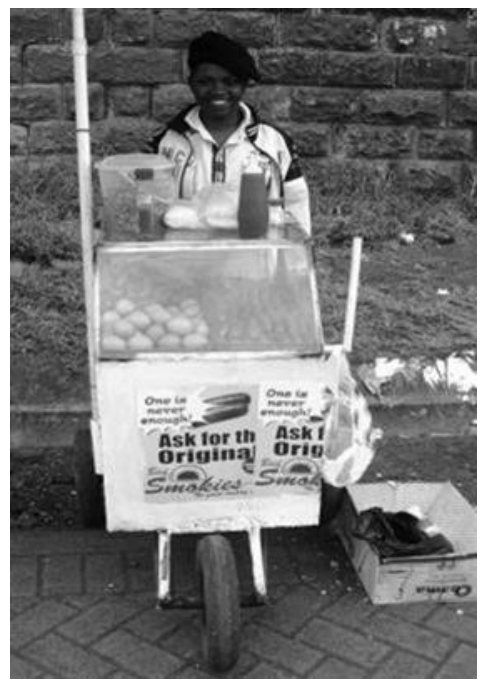

FIGURE 1

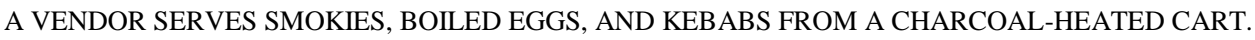

The most common vegetables, roots, and edible plants, were roasted maize, cassava, arrowroots, and potatoes, all of which are high in starch and carbohydrates. Other popular street foods included boiled eggs, popcorn, peanuts, candy, biscuits, and githeri, a hot bean and corn dish. 
TABLE I

TOP FOODS SOLD BY VENDORS

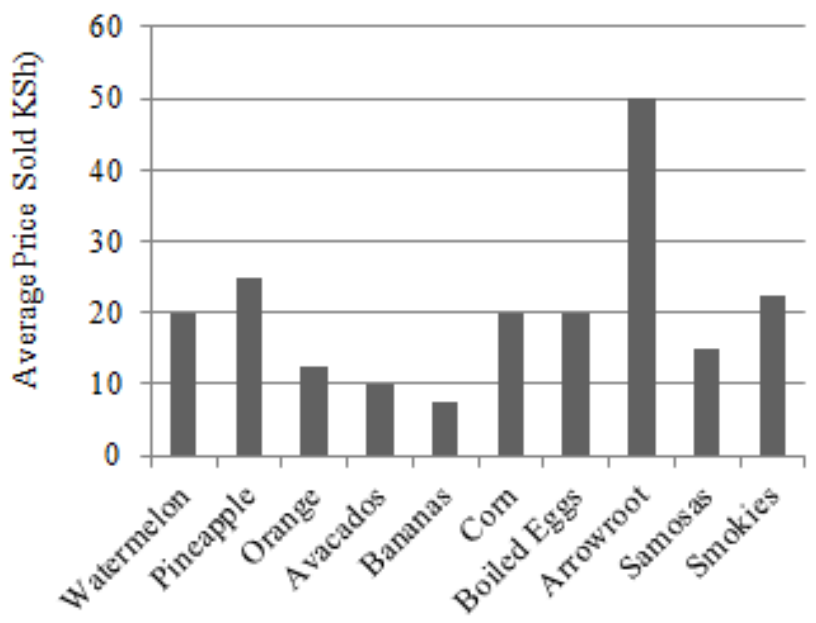

THE TOP TEN STREET FOODS RANKED BY NUMBER OF VENDORS SELLING EACH (IN ORDER, MOST COMMON ON LEFT) AGAINST AVERAGE SALE PRICES.

Menu analyses showed that the majority of small cafés served different appetizers than those offered on the street - in particular more expensive foods, with the only common crossover foods being smokies (miniature sausage), githeri (hot bean and corn dish), samosas (fried vegetable/meat pastry), mandazi (fried doughnut), and arrowroot.

TABLE II

COMPARISON OF AVERAGE FOOD PRICES IN SHILLINGS (KSH)

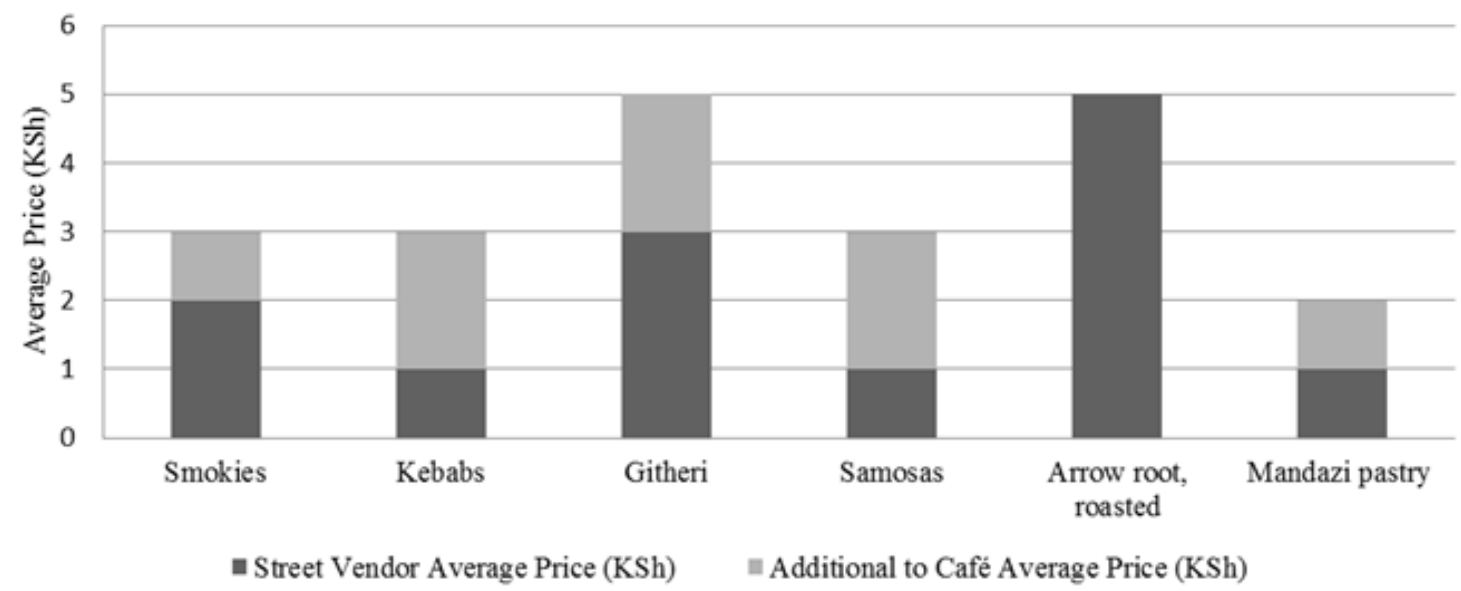

While the prices and preparation methods of these foods were similar to street foods, small cafés offered a larger variety of snack foods, including those that required more sophisticated preparation and thus were more expensive. Even these additional snack foods still visibly lacked 
a variety of nutrients, however, based on their deep fried, carbohydrate-based nature. Some of these foods include ugali (a porridge or dough-like flour dish), bhajia (a fried vegetable fritter), and chapatti (a flatbread similar to tortillas). These findings show that in addition to street foods, many appetizers offered in restaurants similarly lack a variety of nutrients.

TABLE III

TOP FOODS SOLD BY RESTARAUNTS

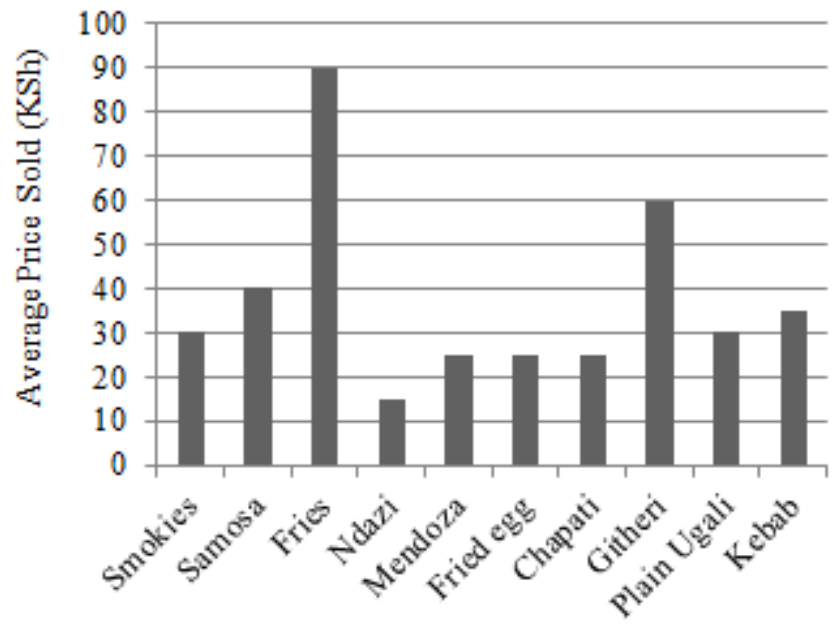

THE TOP TEN APPETIZER FOODS MOST COMMONLY OFFERED IN RESTAURANTS (IN ORDER, MOST COMMON ON LEFT) AGAINST THEIR AVERAGE PRICE.

Street Food Popularity among Vendors

Vendors living in low-income areas can benefit in many ways from entering the street food industry. The most commonly reported motivations for vendors were low start-up costs, social acceptance of other women, low barriers to entry, good customer relationships, and benefits of operating in the informal sector. 


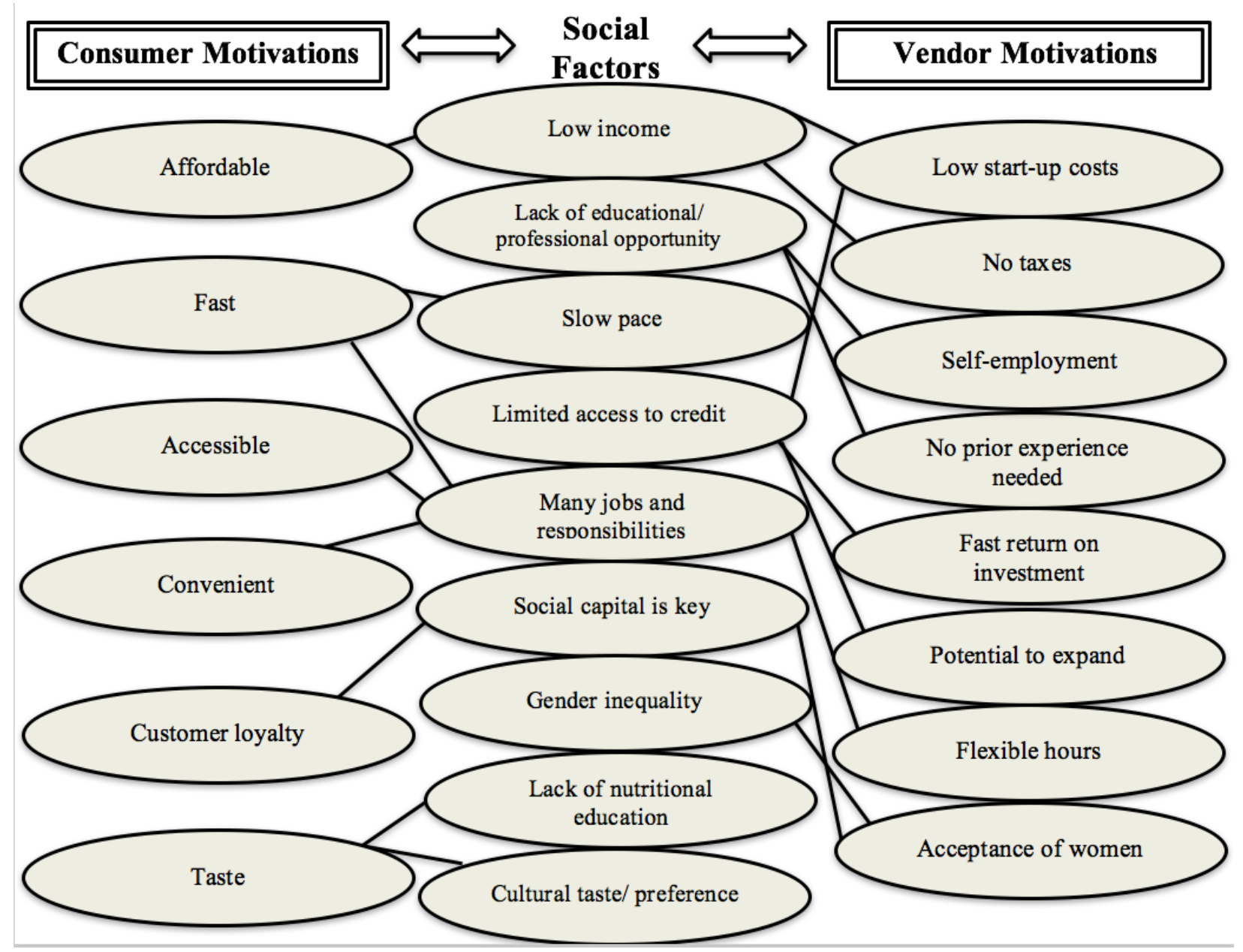

FIGURE 2

VENDOR MOTIVATIONS TO SELL STREET FOODS AND CONSUMER MOTIVATIONS TO BUY STREET FOODS ARE DIRECTLY LINKED TO CURRENT SOCIAL REALITIES.

\section{Low Barriers to Entry and Social Acceptance of Women}

The low barriers to entry in street vending allow individuals with limited education or experience to earn an income. ${ }^{12}$ Street vendors are their own bosses - they are entrepreneurs who make their own hours, keep their profits, and have the freedom to make final decisions about business management. ${ }^{1}$ In addition, street vending is a beneficial livelihood in many regions of the world because both men and women are socially accepted. Women comprise more than two-thirds of street vendors in the main cities of Togo, Mali, Ghana, Benin, and Côte D'Ivoire, and more than half in Madagascar, Kenya, South Africa, and Senegal. ${ }^{13}$ In Senegal, 59\% of female street food vendors are the sole source of income for their families; in Egypt 55\%, and in Thailand, 20\%.2 The following case studies depict ways in which male and female Nyeri street vendors have personally and professionally benefitted from the street food sector. 
Street Food Vendor: Case Study \#1

Francis, a Nyeri native, grew up with little money and education and started working as a houseboy for a wealthier household to support his family at the age of 13. At 24, Francis was obliged to consider a less risky investment after spending 10,000 KSh (approximately 100 USD) on a hotel that went out of business several months later. He began his new career in 2005 as an unlicensed street food vendor, selling pineapple slices from a plastic container. "After some time, I was able to buy more variety of produce and also more tools. I was good at building things so I used 3,000 KSh to create my stand from a crate and wheels." As a result of low barriers to entry, Francis was able to enter the street vending industry with ease despite his lack of education. The business's low start-up costs and Francis's ability to make managerial decisions provided him the opportunity to start with a small capital investment and later upgrade from a bucket to a cart. Francis has since recovered his lost investment and is able to help support his wife, another street vendor, and their two kids. By becoming self-employed in the street food sector soon after his financial troubles, Francis was able to quickly regain a sense of financial security.

Street Food Vendor: Case Study \#2

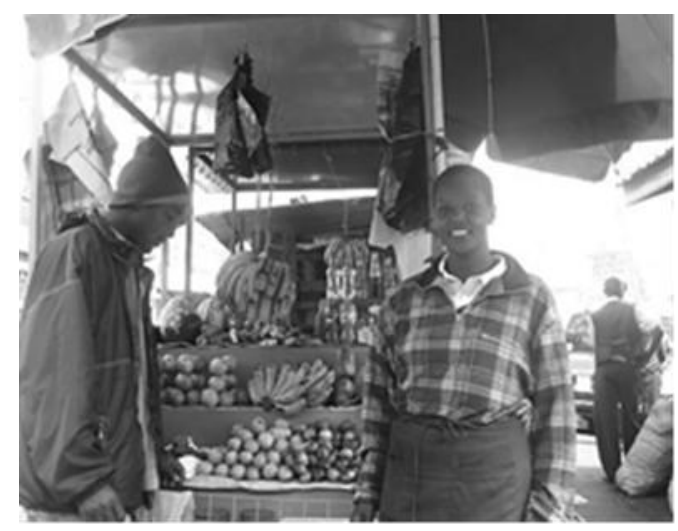

FIGURE 3

ESTER ATTENDS TO HER STAND WHERE SHE SELLS PRODUCE, DRINKS, AND BISCUITS.

Ester, a food vendor of ten years, began a career in Nyeri selling secondhand clothes with her husband. After getting divorced and finding herself with no source of income, Ester joined dozens of fellow entrepreneurs in the Nyeri market to sell produce and other goods from a wooden stand. After six years, Ester moved her business to a more popular location where she could make higher profits, despite the increase in licensing fees. In conjunction with her move, Ester secured a bank loan to purchase a new cart at a discounted rate of 3,000 KSh from a friend who could no longer maintain the business. Ester became self-employed by this route due to the acceptance of women in the street food industry. "Here, there are not many women who are divorced and work, so selling foods on the street helped me to become independent to make money. It was good because I was having trouble to find a job at the time." 


\section{Benefits of Informal Sector Self-Employment}

The majority of street vendors are considered part of the informal sector because a substantial number of them operate without licenses or permits. ${ }^{3}$ While the majority of unlicensed vendors reap the benefits of not having to pay income taxes, they are not afforded any formal employee benefits that licensed vendors are provided by the government, such as life insurance, sick leave or paid vacations, nor are they protected by labor laws. ${ }^{3}$ Many vendors in developing countries sacrifice these formal corporate benefits due to local enforcement conditions, lower informalsector startup costs, and direct profit retention.

\section{Street Food Popularity among Consumers}

Among 50 consumers approached on the street, ages 20 through 70, 76\% reported eating street foods at least once a week, for various motivations. Overall, $25 \%$ reported eating street foods as often as five to six times per week, $10 \%$ reported only two to three times a month, and less than $5 \%$ reported never.

TABLE IV

\section{AGE BRACKETS OF INTERVIEWEES WHO REPORTED EATING STREET FOODS AT} LEAST ONCE PER WEEK

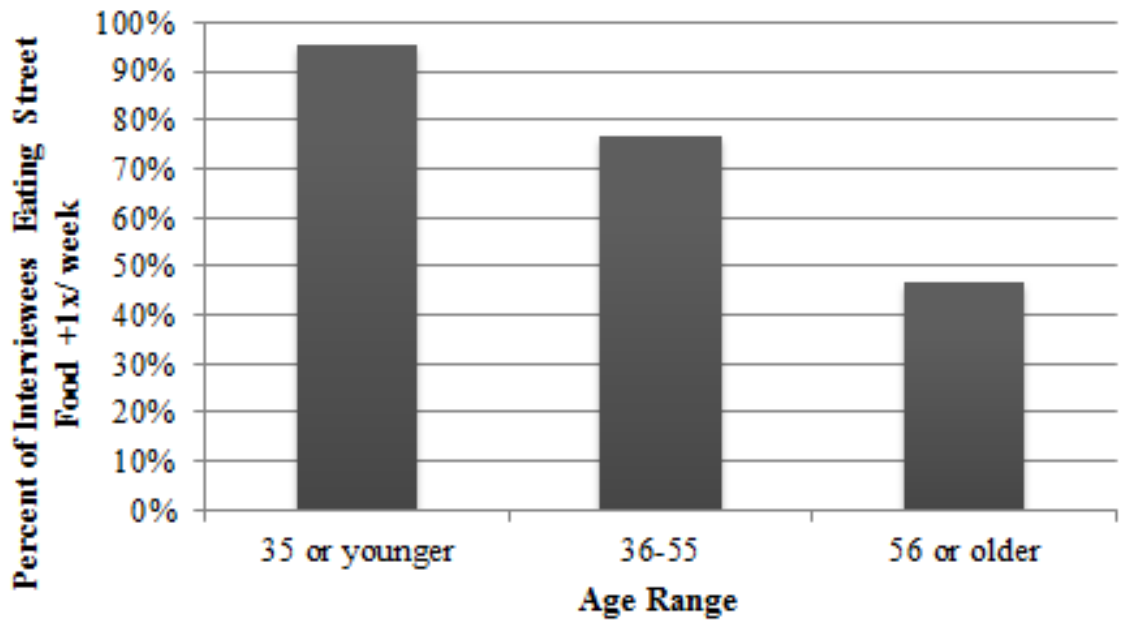

In Table IV, individuals were categorized into three age groups and coded either as eating street foods at least once per week or less than once per week. Explanations that several consumers, mostly of older age, provided for not eating street foods included: lack of sanitation, concerns for their own health, and the luxury of being able to afford most restaurants. Where individuals chose to buy their food depended on a number of factors such as diet, budget, taste preferences, and proximity. The following case studies provide personal narratives to illustrate motivations for food purchasing preferences and to depict themes of street food benefits identified. 
International Journal for Service Learning in Engineering, Humanitarian Engineering and Social Entrepreneurship Vol. 11, No. 2, pp. 87-100, Fall 2016

ISSN 1555-9033

Street Food Consumer: Case Study \#1

As a male university student in his early 20s, Ajasa eats street foods four to five times per week, usually purchasing samosas, smokies, kebabs, boiled eggs, or maize for 20-40 KSh each. "There is a cafeteria in my university, but I do not buy food from there often because it is so expensive." Street foods are conveniently located all around the university, fast enough to pick up in-between classes, substantially more affordable than foods offered in the cafeteria, and tasty. When purchasing fruit in the open market, Ajasa purchases from his friend's mom who gives him a discount because of their relationship and his loyalty.

Street Food Consumer: Case Study \#2

Eunice is a woman in her mid-40s who has been consuming street food since childhood and relies on it four to five times a week to feed her three children. As a result of her hectic work schedule, Eunice does not have time to prepare her children's meals every day. "I give them a little money every morning before school to buy some lunch or snacks from the vendors and they like to eat outside food too." Aside from the convenience, portability, and cost, Eunice also relies on street foods when, "[she's] in a rush, without time to sit down for a meal, which can take several hours in Nyeri."

\section{DISCUSSION}

\section{Supply Chain and Concept of Operations}

Primary observations and interviews found that the majority of vendors are not offering much variety. Due to high competition, vendors are forced to sell their products at standardized prices that consumers are accustomed to paying. The majority of vendors maximize their profit margins by purchasing in bulk from local produce markets or supermarkets. Specifically, many vendors reported purchasing ingredients from farmers markets, the Nyeri town center, wholesale markets, distribution centers, and nearby towns such as Karatina. Vendors purchased their carts from timber yards, metal stores, and jua kali centers, which are markets selling goods and services in the informal sector. The majority of vendors kept their cart or stand stationary and paid a permit fee of $15 \mathrm{KSh}$ per day. Before work, vendors visit a worker permit center to pay the daily, monthly, or annual fee in order to avoid being fined. While some of the vendors did not report buying a license, their vending location was not permanent, usually carrying a plastic basket of sliced fruit.

The frequency with which vendors purchase ingredients varied based on the type of food they sold. For more popular products such as produce and smokies, vendors restocked daily. For products that have a longer shelf life such as dry foods and are not as commonly consumed, such as popcorn and peanuts, vendors restock once a week or less. In order to sell all the items and prevent waste, Nyeri food vendors offered discount prices when foods began to surpass their shelf life. The vendors who reported making higher profits offered a larger variety of foods, were more likely to sell fresh foods such as fruit and vegetables, and were more likely to buy inseason produce. Foods in season are cheaper to purchase and more popular with consumers because of their low price.

According to vendor interviews, the main leverage points for maintaining a successful business are the cost of ingredients, the selling price, and food preservation. Many vendors needed to purchase materials and raw foods at low prices due to limited access to capital. 
International Journal for Service Learning in Engineering, Humanitarian Engineering and Social Entrepreneurship Vol. 11, No. 2, pp. 87-100, Fall 2016

ISSN 1555-9033

Vendors tended to purchase their foods between two and six days a week, and thus needed cash on these days. The frequent purchasing behavior of vendors was due to a general lack of refrigeration. Without refrigeration or other sophisticated preservation methods, vendors typically constrained themselves to foods with an unrefrigerated shelf life of at least one week. The life of a street food once fully prepared was significantly shorter than this - often just one day. Thus, final preparations must be simple enough to conduct daily, and prepared foods need to be sold within one day. If vendors wish to adopt healthier foods, issues related to utilizing new ingredients, setting prices, and preserving foods will have important economic or social significance.

\section{Limitations and Future Recommendations for Improving the Street Food System in Sub-Saharan} Africa

Though some in the formal sector consider street vending an illegitimate livelihood, the sector nonetheless strongly influences consumer nutrition and employment for low-income populations. Thus, in order to improve local economies, it is important to improve nutrition, train vendors on food-handling sanitation, and strengthen legal protections for the industry.

Educating vendors and consumers on the health benefits of a balanced diet, consisting of sufficient intake from all food groups, can facilitate incorporating nutrition into street foods. Efforts can include community seminars, classes, or flyers, among other context-specific methods. Because vendors are limited to inexpensive foodstuffs and simple preparation, potential improvements should focus on practical improved preparation methods and food variations that add nutritional value while sustaining businesses.

Nutritional improvement and innovation will come from creating new methods and processes that combine ingredients and fortifications into healthier end products. These methods must be designed for quick preparation, but should still incorporate a variety of micronutrients from a range of sources. Further, cost is not the sole limiting factor in the consumption of healthier foods - the healthiest foods on the small café and restaurant menus were not the most expensive items. Increasing consumer awareness of healthier food options will create the necessary market demand, urging food suppliers and vendors to offer healthier options. ${ }^{14}$

Nutritional augmentation will also be more feasible if street vendors work alongside organizations to build advocacy and education programs that improve nutritional awareness and promote their local businesses. Effective advocacy could result in increased legal protections, such as involving community health workers and public officials in monitoring quality control, which in return will lead to increased sanitation standards. Other legal protections could include lessening the uncertainty of yield week to week via setting target profits, as well as formally recognizing the space of each vendor and reducing evictions. These positive ripple effects such as improving social standing could also help expand the customer base for street foods, enabling vendors to diversify into more nutritious offerings even if they are more expensive. This greater integration into the market and community could further entice street food vendors to satisfy their customers in terms of price, nutrition, sanitation, and taste.

The opportunity exists to innovate upon simple technologies in order to introduce techniques for improving nutrition, food preservation and storage, and ultimately, vendor profits. While refrigeration and freezers are a simple technology in resource-rich settings, they are highly costprohibitive for street vendors in settings such as Kenya. Nevertheless, simple food preservation technologies can be implemented at fairly low costs to vastly improve food storage and profit 
margins for these low-income vendors. Solar dryers, for instance, would allow vendors to purchase produce in bulk at a lower per-unit price while keeping food safe and vendible for longer. Other techniques and technologies to improve food preservation could include canning or use of chemical additives.

A re-design of food carts could allow for optimization of cart space - organizing compartments within a cart that are dry and cool could allow for improved storage of foods in various stages of processing. Another food cart improvement may adapt the cooking space to change the ways foods are cooked on the streets through use of modified stoves, kerosene, and batteries. Using household items such as blenders, shakers, and filters to produce juices and beverages on the street is broadening vendor success in areas such as Dhaka, Bangladesh. ${ }^{14}$ By innovating on the cooking space to improve cooking heat, time, or reduce the amount of oil needed, the opportunities for street vendors can widen to allow for more variety in products sold and less food waste. Foods could be prepared to-order, instead of in bulk and warmed throughout the day. This change also has the potential to improve food safety and reduce foodborne disease transmission.

If street vendors are able to improve business methods, work alongside key stakeholders, and consider the potential improvements mentioned above, there is an opportunity to improve this informal sector in developing countries with high rates of street food consumption.

\section{CONCLUSION}

This study describes a variety of motivations for vendors and consumers involved in the street food industry, concluded from literature reviews, interviews with vendors and consumers in Kenya, and analyses of restaurant menu items. The most popular street foods in the market share a few underlying qualities - mainly low price, simple preparation requirements, and long shelf life. In order to advance the industry, efforts should be concentrated on integration into public and formal sectors, and leveraging these relationships to improve nutrition through social and technological adaptations. However, these efforts should not compromise the low capital and education requirements that attract many vendors to the industry in the first place. An additional consideration is that the majority of street food consumers do not take nutrition into consideration when making purchasing decisions, given that very few of them mentioned this as a deciding factor when purchasing street foods. If street foods are to improve health consciousness and sanitation while maintaining sustainable businesses and reaching their target market, consumers must become more knowledgeable about the benefits of consuming a balanced diet and vendors must adapt their businesses to emphasize both nutrition and affordability. 
International Journal for Service Learning in Engineering, Humanitarian Engineering and Social Entrepreneurship Vol. 11, No. 2, pp. 87-100, Fall 2016

ISSN 1555-9033

\section{REFERENCES}

${ }^{1}$ Peter Fellows and Martin Hilmi, Selling Street and Snack Foods (Rome, Italy: Food and Agriculture Organization, 2002), accessed May 1, 2016, http://www.fao.org/docrep/015/i2474e/i2474e00.pdf.

${ }^{2}$ Irene Tinker, "Street Foods into the 21st Century." Agricultural and Human Values 16 (1999): 327, accessed May 1, 2016, http://irenetinker.com/publications-and-presentations/street-foods.

${ }^{3}$ Monique Cohen, Mihir Bhatt and Pat Horn, Women Street Vendors: The Road to Recognition (New York, USA: The Population Council, 2000), accessed May 1, 2016, http://wiego.org/sites/wiego.org/files/publications/files/Cohen-Bhatt-Horn-Women-Street- Vendors-SEEDS.pdf.

${ }^{4}$ Mary Oyunga-Ogubi, NJ Waudo, A Afullo A and SO Oiye, "Street Foods in Nairobi, Kenya: Their role as a source of micronutrients in low income groups." The African Journal for Food, Agriculture, Nutrition and Development 9 (2009): 208-216, accessed May 1, 2016, http://www.fao.org/fileadmin/user_upload/fsn/docs/Street_Foods/Street_Foods_Kenya_Oyunga-Ogubi.pdf.

${ }^{5}$ RJ Dawson, RJ. and C Canet, "International Activities in street foods" Street Foods Book 86, (1991), 135-139.

${ }^{6}$ Khanjan Mehta, L Semali and Audrey Maretzki , "The Primacy of Trust in the Social Networks and Livelihoods of Women Agro-Entrepreneurs in Northern Tanzania." The African Journal for Food, Agriculture, Nutrition and Development 11 (6) (2011): 1-13, accessed May 1, 2016, http://www.ajol.info/index.php/ajfand/article/view/72676/61594.

${ }^{7}$ FAO, IFAD and WFP. 2015. The State of Food Insecurity in the World 2015. Meeting the 2015 international hunger targets: taking stock of uneven progress. Rome, FAO. http://www.fao.org/3/a-i4646e.pdf

${ }^{8}$ Marilyn Massey-Stokes M and Anna Love, "Food, Cuisine, And Cultural Competency For Culinary, Hospitality, And Nutrition Book, Jones and Bartlett Publisher, (2011), 375-377.

${ }^{9}$ Institution of Mechanical Engineers, and IMechE, “Global food: Waste not, want not.” (2013), accessed May 1, 2016. https://of-imeche.olib.oclc.org/folio/.

${ }^{10}$ Ryzia De Cssia Vieira Cardoso, Michele Companion, and Stefano Roberto Marras, Street Food: Culture, Economy, Health and Governance (London and New York: Routledge Studies in Food, Society, and the Environment, 2014), accessed May 1, 2016, https://www.routledge.com/Street-Food-Culture-economy-health-and- governance/Cardoso Companion-Marras/p/book/9781138023680.

${ }^{11}$ Nago S, Lachat C, Huybregts L, Roberfroid D, Dossa R and PW Kolsteren, "Food, Energy And Macronutrient Contribution of Out-of-Home Foods in School-Going Adolescents in Cotonou, Benin.” (2010) The British Journal of Nutrition, 103 (2), accessed June 1, 2016, http://www.ncbi.nlm.nih.gov/pubmed/19818195.

${ }^{12}$ FAO," Improving the Nutritional Quality of Street Foods To Better Meet The Micronutrient Needs of Schoolchildren in Urban Area." (FAO, Rome, 2007: 1-45, accessed June 1, 2016). http://www.fao.org/3/a-ag430e/.

${ }^{13}$ International Labour Organization. (2002) Women and Men in the Informal Economy: A Statistical Picture, (Report 978-92-2-128170-2, Geneva, Switzerland.) Accessed May 1, 2016 , http://www.ilo.org/wcmsp5/groups/public/---dgreports/--stat/documents/publication/wcms_234413.pdf. 
International Journal for Service Learning in Engineering, Humanitarian Engineering and Social Entrepreneurship Vol. 11, No. 2, pp. 87-100, Fall 2016

ISSN 1555-9033

${ }^{14}$ S M Alauddin, July 21, 2015, "The impact of technology on street food vendors, "Practical Action Blog, accessed May 1, 2016, http://practicalaction.org/blog/news/the-impact-of-technology-onstreet-food-vendors/. 